\title{
Erratum to: Mechanisms by which HIV envelope minimizes immunogenicity
}

\author{
Haixiang Jiang • C. Garren Hester • Larry Liao • \\ David C. Montefiori • Michael M. Frank
}

Published online: 12 January 2011

(C) Springer Science+Business Media, LLC 2011

\section{Erratum to: Immunol Res \\ DOI 10.1007/s12026-010-8178-6}

Unfortunately, the second author Dr. C. Garren Hester was left in the original version. The correct version of author list is provided in this erratum.

The online version of the original article can be found under doi:10.1007/s12026-010-8178-6.

H. Jiang · C. G. Hester · M. M. Frank $(\bowtie)$

Department of Pediatrics, Duke University Medical Center, Durham, NC, USA

e-mail: frank007@mc.duke.edu

L. Liao - M. M. Frank

Department of Medicine, Duke University Medical Center, Durham, NC, USA

D. C. Montefiori · M. M. Frank

Department of Immunology, Duke University Medical Center, Durham, NC, USA

D. C. Montefiori

Department of Surgery, Duke University Medical Center, Durham, NC, USA 